\title{
SESSION III
}

\author{
Chairman: Professor J. G. Scadding, M.D., F.R.C.P.
}

\section{General considerations in intermittent drug therapy of pulmonary tuberculosis}

\author{
WALLACE FOX \\ M.R.C. Tuberculosis and Chest Diseases Unit, Brompton Hospital, London, S.W.3
}

\begin{abstract}
Summary
The advantages of intermittent chemotherapy for pulmonary tuberculosis are discussed and the results of several controlled trials summarized. Once-weekly therapy now appears a definite prospect.

The most appropriate approach to therapy at both national and individual physician level now seems to be a combination of unsupervised daily and supervised intermittent regimens.
\end{abstract}

Fully intermittent chemotherapy for pulmonary tuberculosis is by no means new. As long ago as 1947, Corper \& Cohn studied streptomycin intermittently in guinea-pig tuberculosis and reported promising results. In the early 1950 s other workers studied isoniazid, streptomycin and viomycin intermittently in mouse and in guinea-pig tuberculosis and again reported promising results (Grumbach, Rist \& Riebel, 1952; Hobby \& Lenert, 1953; Palmer, Ferebee \& Hopwood, 1956). On the clinical side, intermittency from the very start of treatment was first reported on by James and others 20 years ago. They studied streptomycin intermittently and found it promising. Other workers in the early 1950s studied streptomycin plus PAS (Tempel et al., 1950), isoniazid (Frimodt-Moller et al., 1953) and streptomycin plus isoniazid (Chambers et al., 1955). Fully intermittent regimens as continuation chemotherapy after an initial intensive phase of daily chemotherapy was studied in the early 1950 s by Mackay-Dick and his colleagues $(1954,1959)$ and in a Medical Research Council study reported by Hutton et al. (1956). Those groups used streptomycin plus isoniazid. At that time, however, none of us appreciated the importance of the observations we were making.

The potentiality of intermittency was overlooked for a number of reasons. First it had been established that an intermittent and a daily drug formed inadequate combinations, both for streptomycin intermittently with daily PAS (Mount \& Ferebee, 1953) and for streptomycin intermittently with daily isoniazid(Medical Research Council, 1955;Schwartz, 1956). Secondly, some of the early studies did not include isoniazid, the most suitable drug for intermittency. Further, the size of the individual doses of drugs was sometimes too small. Most important of all, however, was the absence of a sound scientific basis in man to explain the likely mechanism of action of intermittent regimens.

A sound scientific basis arose first, from a very important investigation from the Chemotherapy Centre, Madras, which was reported in 1960. In this investigation it was found that $400 \mathrm{mg}$ of isoniazid a day given as a single dose was more effective than $400 \mathrm{mg}$ of isoniazid a day given in two doses, even although the latter regimen produced continuous inhibitory levels of isoniazid in the serum and the former did not (Gangadharam et al., 1961). It was thus quite clear that the high individual dose of isoniazid was producing its effect by damaging tubercle bacilli in a way that at that time we had not yet appreciated. Subsequently, further clinical studies were undertaken in Madras and these have given us clearer information on the mechanisms of action of intermittent regimens on the clinical side and particularly on the role played by the rate of inactivation of isoniazid (Tuberculosis Chemotherapy Centre, Madras, 1970; Tripathy, 1970) and this has been backed up by important experimental work both in vivo and in vitro (Dickinson \& Mitchison, 1966a, 1966b; Dickinson, Ellard \& Mitchison, 1968; Mitchison, 1970) by Professor Mitchison's group and also by the in vivo studies of the Pasteur Institute group (Grumbach, 1962; Canetti, Grumbach \& Grosset, 1963; Grumbach, Canetti \& Grosset, 1964; Grumbach et al., 1967; Grumbach, Canetti \& Le Lirzin, 1969). 
Thus, modern intermittent chemotherapy did not arise in an empirical way and for more than a decade it has been under study by some groups following carefully planned lines of research with a sound scientific basis.

\section{The advantages of intermittent therapy}

The advantages of intermittent regimens over daily regimens are:

(1) They are usually less toxic.

(2) They are entirely supervisable so that concealed irregularity is impossible. If a patient attends for his supervised intermittent regimen then he receives it and it is known that he has received it. If he fails to attend then it is known that a dose of the regimen has not been administered. Hence it is possible to take immediate action to contact the patient. The position is very different from the relatively little positive control which can be exercised over a patient on self-medication, however well-organized the supervision by urine testing and checks of the stocks of oral medicament may be.

(3) Intermittent chemotherapy can be at least as effective and possibly, in some circumstances, even more effective than daily regimens, as studies referred to below have demonstrated.

The question of toxicity merits further consideration. In Table 1 the toxicity for the same dosage of streptomycin or sodium PAS given daily or twice a week is set out. When streptomycin 1 or $2 \mathrm{~g}$ were given daily for a period of 4 months, toxicity was encountered in $58 \%$ of the patients in a 4-month period, but in only $5 \%$ given the same dose size twice a week (Tempel et al., 1950). For sodium PAS a recent study in Madras (Ramakrishnan, 1971) has reported that $10 \mathrm{~g}$ a day produced major drug toxicity severe enough to necessitate stopping the regimen in $6 \%$ of the patients. In contrast no patient on the same dosage twice-weekly had to stop the drug on account of toxicity. There were also substantial differences between the regimens in the incidence of minor drug toxicity (Tripathy, 1971).

The individual dose sizes of drugs which have been administered in daily and in intermittent regimens fall into three groups (Table 2). Streptomycin, sodium PAS and ethionamide (Fox et al., 1969; Devadatta et al., 1970) are drugs in which the conventional daily dose and the highest intermittent dose which can be given are of the same order, because a limitation on the size of the individual dose is set by the occurrence of acute toxicity. At the other extreme there are drugs such as isoniazid, pyrazinamide and ethambutol in which the highest intermittent dose which can be used is several times the conventional daily dose. Thus, whereas isoniazid is given in a dose of 3-5 mg/ $\mathrm{kg}$ daily, an intermittent dose of $15 \mathrm{mg} / \mathrm{kg}$ can be given twice a week (Tuberculosis Chemotherapy Centre, Madras, 1964) or once (Tuberculosis Chemotherapy Centre, Madras, 1970), about a four-fold increase. For pyrazinamide about a five-fold increase can be given at a onceweekly frequency (Tuberculosis Chemotherapy Centre, Madras, 1970) and for ethambutol we have unpublished data from Hong Kong and from Madras (Tripathy, 1971) that about a six-fold increase when given once-weekly is a safe level. Then there is an intermediate group of drugs represented by thiacetazone and rifampicin. For the former we have unpublished evidence that it is certainly possible to increase the size of the individual doses from 150 $\mathrm{mg}$ to $300 \mathrm{mg}$ in twice-weekly intermittency and possibly even higher. For rifampicin it may be possible to increase the dose to nearly double the con ventional daily dose (Decroix et al., 1971) although there is increasing evidence from many parts of the world (Stradling, 1971) (nearly all as yet unpub@ lished, although much should appear in the Proceedings of the Moscow (1971) Conference of the International Union Against Tuberculosis) that doubling the dose and giving the drug intermittentlis: may sometimes lead to serious toxicity. Indeed? there is a possibility that rifampicin given intermittently may, itself, without an increase in the size of the individual dose, produce toxicity.

\section{Results of controlled trials}

The important controlled trials in the world literature of twice-weekly fully intermittent regimens of chemotherapy for newly-diagnosed pulmonary disease are summarized in Table 3 which is restricted to comparisons reported beyond 6 months. The first study is the classic study from the Tuberculosis Chemotherapy Centre, Madras, reported in 1964, in which a daily unsupervised regimen of PAS plus isoniazid in standard dosage was compared with streptomycin $1 \mathrm{~g}$ plus high dosage $(15 \mathrm{mg} / \mathrm{kg}$ bodyweight) isoniazid twice a week in severe sputumpositive cavitated disease. Both regimens were given

TABLB 1. Drug toxicity with same dosage of a drug administered daily or twice weekly

\begin{tabular}{|c|c|c|c|c|c|c|}
\hline \multirow[b]{2}{*}{ Drug } & \multirow[b]{2}{*}{$\begin{array}{c}\text { Dosage } \\
\text { (g) }\end{array}$} & \multicolumn{2}{|c|}{ Daily } & \multicolumn{2}{|c|}{ Twice-weekly } & \multirow[b]{2}{*}{ Study } \\
\hline & & $\begin{array}{l}\text { No. of } \\
\text { patients }\end{array}$ & $\begin{array}{c}\text { Toxicity } \\
(\%)\end{array}$ & $\begin{array}{l}\text { No. of } \\
\text { patients }\end{array}$ & $\begin{array}{c}\text { Toxicity } \\
(\%)\end{array}$ & \\
\hline $\begin{array}{l}\text { Streptomycin } \\
\text { Sodium PAS }\end{array}$ & $\begin{array}{l}1 \text { or } 2 \\
10\end{array}$ & $\begin{array}{r}66 \\
109\end{array}$ & $\begin{array}{r}58 \\
6\end{array}$ & $\begin{array}{r}97 \\
111\end{array}$ & $\begin{array}{l}6 \\
0\end{array}$ & $\begin{array}{l}\text { Tempel et al. (1950) } \\
\text { Ramakrishnan (1971) }\end{array}$ \\
\hline
\end{tabular}


TABLE 2. Dose size of drugs in daily and intermittent regimens

\begin{tabular}{llll}
\hline \multicolumn{1}{c}{ Drug } & $\begin{array}{c}\text { Conventional } \\
\text { daily dose }\end{array}$ & $\begin{array}{c}\text { Highest } \\
\text { intermittent } \\
\text { dose used }\end{array}$ & $\begin{array}{c}\text { Doses } \\
\text { a week }\end{array}$ \\
\hline Streptomycin & $0 \cdot 75-1 \mathrm{~g}$ & $0 \cdot 75-1 \mathrm{~g}$ & Two or one \\
Sodium PAS & $10-12 \mathrm{~g}$ & $10-12 \mathrm{~g}$ & Two \\
Ethionamide & $0.5-1 \mathrm{~g}$ & $0.5-1 \mathrm{~g}$ & Two \\
Thiacetazone & $150 \mathrm{mg}$ & $300 \mathrm{mg}$ or more Two \\
Rifampicin & $450-600 \mathrm{mg}$ & $900-1200 \mathrm{mg}$ & Two or one \\
Isoniazid & $3-5 \mathrm{mg} / \mathrm{kg}$ & $15 \mathrm{mg} / \mathrm{kg}$ & Two or one \\
Pyrazinamide & $20-30 \mathrm{mg} / \mathrm{kg}$ & $90 \mathrm{mg} / \mathbf{k g}$ & One \\
Ethambutol & $15-20 \mathrm{mg} / \mathrm{kg}$ & $90 \mathrm{mg} / \mathrm{kg}$ & One \\
\hline
\end{tabular}

without an initial intensive phase and at 1 year quiescent disease was achieved in $94 \%$ of the patients on the twice-weekly regimen compared with $85 \%$ of the patients on the daily regimen. In the International Union Against Tuberculosis Investigation (1970), after an initial intensive phase of 1 month with streptomycin plus isoniazid plus thiacetazone, thiacetazone plus isoniazid daily was compared with streptomycin plus high dosage $(750 \mathrm{mg})$ isoniazid twice a week in the continuation phase. The results at 1 year were very similar, both regimens being highly effective. Lahlou (1970) reported a co-operative study in North Africa involving centres in Morocco, Tunisia and Libya, in which ethionamide $(750 \mathrm{mg})$ plus isoniazid $(750 \mathrm{mg}$ ) twice a week was compared with streptomycin plus high dosage isoniazid (750 $\mathrm{mg}$ ) twice a week. This is an important study, being the first report of a fully oral intermittent regimen studied in a controlled clinical trial. The two regimens in this study were compared in the continuation phase, following 1 month of initial intensive chemotherapy with streptomycin plus ethionamide plus isoniazid. Although the handling of the data is open to criticism, nevertheless the culture results at 8 months were very similar for the two series. However, a further study reported by Lahlou (1970) suggested that if the dose size of ethionamide was reduced from $750 \mathrm{mg}$ to $500 \mathrm{mg}$ the intermittent regimen was much less effective. Decroix et al. (1971) have found little difference at 12 months between daily rifampicin $600 \mathrm{mg}$ plus isoniazid $450 \mathrm{mg}$ and twice-weekly rifampicin $900 \mathrm{mg}$ plus isoniazid $750 \mathrm{mg}$ in a relatively small number of patients and with no initial intensive phase.

Two further important recent investigations, not yet reported in full, with which the Medical Research Council has been associated, merit description in fuller detail. The first investigation was undertaken in the Central Bohemian region of Czechoslovakia (Polansky, 1970; Czechoslovakian Tuberculosis Service/World Health Organisation/British Medical Research Council Co-operative Investigation, 1971). After 3 months of classical triple chemotherapy with streptomycin plus PAS plus isoniazid daily, patients were allocated at random to continuation chemotherapy either with daily PAS plus isoniazid in conventional dosage or twice-weekly streptomycin $1 \mathrm{~g}$ plus high dosage $(15 \mathrm{mg} / \mathrm{kg})$ isoniazid. The organization of this study is of particular interest. The Central Bohemian region surrounds Prague City and has an area of 4200 square miles and a population of approximately 1,250,000. There are thirtyone chest clinics and eight tuberculosis hospitals in the region and all the hospitals and twenty-eight of the thirty-one chest clinics collaborated. Furthermore, during the period of intake all the patients in the region who were eligible for the study, according to the criteria laid down, were admitted to the investigation, and a special register was kept of all the

TABLE 3. Twice-weekly fully intermittent regimens for newly diagnosed disease

\begin{tabular}{|c|c|c|c|c|}
\hline Study & Regimens & $\begin{array}{l}\text { Initial } \\
\text { intensive } \\
\text { phase } \\
\text { (months) }\end{array}$ & $\begin{array}{l}\text { No. of } \\
\text { patients }\end{array}$ & $\begin{array}{c}\text { Quiescent } \\
\text { disease } \\
\text { at } 1 \text { year } \\
(\%)\end{array}$ \\
\hline Tuberculosis Chemotherapy Centre, Madras (1964) & $\begin{array}{l}\text { PH daily } \\
\text { SH bi-weekly }\end{array}$ & 0 & $\begin{array}{l}72 \\
66\end{array}$ & $\begin{array}{l}85 \\
94\end{array}$ \\
\hline International Union Against Tuberculosis (1970) & $\begin{array}{l}\text { TH daily } \\
\text { SH bi-weekly }\end{array}$ & 1 & $\begin{array}{c}136 \\
99\end{array}$ & $\begin{array}{l}93 \\
88\end{array}$ \\
\hline Decroix et al. (1971) & $\begin{array}{l}\text { RH daily } \\
\text { RH bi-weekly }\end{array}$ & 0 & $\begin{array}{l}39 \\
41\end{array}$ & $\begin{array}{l}92 \\
88\end{array}$ \\
\hline $\begin{array}{l}\text { Czechoslovakian Tuberculosis Service/World Health } \\
\text { Organisation/British Medical Research Council (1971) }\end{array}$ & $\begin{array}{l}\text { PH daily } \\
\text { SH bi-weekly }\end{array}$ & 3 & $\begin{array}{l}165 \\
233\end{array}$ & $\begin{array}{r}99 \\
100\end{array}$ \\
\hline
\end{tabular}

P, PAS; H, isoniazid; S, streptomycin; T, thiacetazone; E, ethionamide; $R$, rifampicin. * Assessment at 8 months. 
newly-diagnosed cases during the period of the intake to ensure that the coverage was, in fact, complete. In other words, this was an investigation, based on random allocation, of two alternative forms of continuation chemotherapy in all eligible patients diagnosed in the period of intake by all the tuberculosis services of the region. Thus, it was a community investigation of chemotherapy, the first of its kind to be undertaken anywhere in the world.

The bacteriological status at 1 year, based on five or six cultures obtained in the last 3 months from each patient, is summarized in Table 4. Quiescence of the disease was achieved in all except one of the 165 patients on the daily PAS plus isoniazid regimen and all the 233 patients on the twice-weekly supervised intermittent regimen. However, the organization of the daily PAS plus isoniazid regimen was much better than that in all except exceptional centres, even in the technically advanced countries. For example, every patient in the study was due to have two urine specimens collected at surprise visits to the home or place of work each month, in order to test the urine for isoniazid. The visiting was to be undertaken even if it meant five or six visits to obtain a single urine specimen from a patient who was not at home when visited. In fact, the supervisory staff of the dispensaries much preferred the organization of the twice-weekly regimen because they knew the work-load to which they were committed, whereas for the daily unsupervised regimen the collection of urine specimens and efficient supervision of the patients created a considerable and unpredictable work-load.

An important aspect of the organization was its flexibility. A patient could obtain the supervised chemotherapy at a chest clinic dispensary, a doctor's surgery, a health centre, or a hospital near his home, en route to his work or near the place of work, or else a factory dispensary-whichever was most convenient. If necessary a nurse could visit the patient's home or place of work. Moreover, one facility might be used for one supervised treatment a week and another facility for the second, if this was more con-

TABLE 4. Bacteriological status of the patients at 1 year (Czechoslovakian Tuberculosis Service/WHO/Medical Research Council Co-operative Investigation, 1971)

\begin{tabular}{lrrrrr}
\hline Status & $\begin{array}{c}\text { Daily PAS } \\
\text { plus isoniazid }\end{array}$ & & \multicolumn{1}{c}{$\begin{array}{c}\text { Twice-weekly } \\
\text { streptomycin } \\
\text { plus high } \\
\text { dosage isoniazid }\end{array}$} \\
\cline { 2 - 3 } \cline { 5 - 6 } & No. & $\%$ & & No. & $\%$ \\
\hline Favourable & 164 & 99 & & 233 & 100 \\
Unfavourable & 1 & 1 & & 0 & 0 \\
Total patients & 165 & 100 & & 233 & 100 \\
\hline
\end{tabular}

venient to the patient. Table 5 shows the facility most frequently attended for the supervised chemotherapy by the 232 patients who were on the supervised regimen for at least a month. The majority,

TABLE 5. Average distance travelled and time taken to obtain supervised chemotherapy in 232 pateints on twiceweekly streptomycin plus isoniazid (Czechoslovakian Tuberculosis Service/WHO/Medical Research Council Cooperative Investigation, 1971)

\begin{tabular}{lrrcc}
\hline $\begin{array}{c}\text { Place most frequently } \\
\text { attended for supervised } \\
\text { chemotherapy }\end{array}$ & \multicolumn{2}{c}{ Patients } & $\begin{array}{c}\text { Distance } \\
\text { travelled } \\
\text { (km) }\end{array}$ & $\begin{array}{c}\text { Time } \\
\text { taken } \\
\text { (min) }\end{array}$ \\
\hline No. & $\%$ & & \\
\hline Chest clinic (dispensary) & 154 & 66 & $9 \cdot 7$ & 77 \\
General practitioner & 58 & 25 & 4.8 & 72 \\
Factory clinic & 12 & 5 & 1.3 & 19 \\
Hospital & 3 & 1 & 1.4 & 23 \\
Home & 5 & 2 & 0.0 & 0 \\
\hline
\end{tabular}

$66 \%$, usually attended a chest clinic, $25 \%$ a general practitioner, $5 \%$ a factory clinic, $1 \%$ a hospital and $2 \%$ had their injections in their homes. Because the area was largely rural, the distances travelled were often substantial and the travelling time was more than an hour for the two most frequently useof

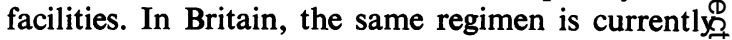
under study in an investigation involving over fift centres. It will be very interesting, in due course, tQ do a corresponding analysis and see how supervisech intermittency is being organized in Britain todaye It can be concluded, however, that streptomycim plus high dosage isoniazid has already been estab lished as an excellent alternative form of continua:tion chemotherapy to standard oral chemotherapy in a technically advanced country and that it may have positive advantages for the patient and the supervisory staff.

The second recent study is a very important one which has been completed in the Chemotherapy Centre, Madras (Ramakrishnan, 1971). The patients in the study had advanced bilateral newly diagnosed disease. They all had an initial 2 weeks of daily triple chemotherapy with streptomycin plus PAS plus isoniazid. They were then allocated at random either to daily sodium PAS $10 \mathrm{~g}$ plus isoniazid $200 \mathrm{mg}$ to be self-administered in two divided doses, or else to sodium PAS $10 \mathrm{~g}$ plus high dosage $(15 \mathrm{mg} / \mathrm{kg}$ bodyweight) isoniazid twice-weekly. The twice-weekly regimen was given under direct supervision as a single dose. The condition of the patients on admission is summarized in Table 6. Moderate, extensive or gross radiographic disease was present in a high proportion of the patients, moderate disease by the classification used in Madras (Tuberculosis Chemotherapy Centre, Madras, 1960) being very far advanced disease. Moderate or extensive cavitation was also present in the majority of patients and nearly 
TABLE 6. Condition of patients on admission to treatment in Madras Study of Intermittent Oral Chemotherapy (Ramakrishnan, 1971)

\begin{tabular}{lcc}
\hline \multicolumn{1}{c}{ Factor } & $\begin{array}{c}\text { Daily PAS } \\
\text { plus isoniazid } \\
\text { regimen }\end{array}$ & $\begin{array}{c}\text { PAS plus } \\
\text { isoniazid } \\
\text { twice- weekly }\end{array}$ \\
\hline Moderate, extensive or gross disease & $73 \%$ & $79 \%$ \\
Moderate or extensive cavitation & $66 \%$ & $73 \%$ \\
Positive smear on first home specimen & $92 \%$ & $90 \%$ \\
Total patients & 92 & 99 \\
\hline
\end{tabular}

every patient had a positive smear on examination of the first specimen of sputum produced overnight in the home and all the patients had positive smear results on the majority of their specimens. The study, therefore, was of severe extensive cavitated sputum positive disease. At 12 months the status was assessed on the basis of nine cultures obtained at 10,11 and 12 months. Quiescent disease was achieved in $87 \%$ of eighty-three patients on the daily regimen and $88 \%$ of ninety patients on the twice-weekly regimen (because these are preliminary analyses the final figures may be slightly modified). Reference has already been made to the fact that $6 \%$ of the patients on the daily regimen stopped treatment on account of drug toxicity compared with no patient on the twice-weekly regimen. There were also fewer minor side-effects on the twice-weekly regimen. Thus, the twice-weekly regimen is at least as effective as the daily regimen and substantially less toxic. Further, there is every reason to believe that if the initial intensive phase had been prolonged beyond the 2 weeks that was given in this study, the twice-weekly regimen of PAS plus high dosage isoniazid might well have been very highly effective indeed, possibly even a so-called ' $100 \%$ ' regimen. It is already clear, on the basis of this Madras study, that this twiceweekly regimen of two long established and widely used standard drugs is a very important advance in intermittent treatment of pulmonary tuberculosis.

Already once-weekly chemotherapy is now a definite prospect. The key investigation which was undertaken in the Tuberculosis Chemotherapy Centre, Madras has been recently (1970) reported. It, too, was a study of newly-diagnosed extensive bilateral cavitated sputum positive disease. Four regimens were investigated, namely:

SHTW-Streptomycin plus high dosage $(15 \mathrm{mg}$ / $\mathrm{kg}$ ) isoniazid, twice a week.

SHOW-Streptomycin plus high dosage isoniazid, once a week.

SHZOW-Streptomycin plus high dosage isoniazid plus high dosage $(90 \mathrm{mg} / \mathrm{kg})$ pyrazinamide, once a week.

SH/SHOW-Streptomycin plus isoniazid (400 $\mathrm{mg}$ ) daily for 4 weeks followed by streptomycin plus high dosage $(15 \mathrm{mg} / \mathrm{kg})$ isoniazid once a week.
(Two dosages of streptomycin, namely $1.0 \mathrm{~g}$ and $0.75 \mathrm{~g}$ were also studied at random.)

Table 7 sets out the status of the patients at 1 year. Quiescent disease was achieved in $94 \%$ of the patients on the twice-weekly regimen whereas the once-weekly SHOW regimen was much less effective, $68 \%$ of the patients attaining quiescent disease.

TABLE 7. Status of patients at 1 year in Madras Study of once-weekly chemotherapy (1970) (based on seven to nine cultures at 10,11 and 12 months)

\begin{tabular}{lcccc}
\hline Status of disease & SHTW & SH/SHOW & SHZOW & SHOW \\
\hline Quiescent & $94 \%$ & $88 \%$ & $74 \%$ & $68 \%$ \\
Active & $4 \%$ & $12 \%$ & $23 \%$ & $32 \%$ \\
TB death & $1 \%$ & $0 \%$ & $2 \%$ & $1 \%$ \\
Total patients & 96 & 101 & 101 & 77 \\
\hline
\end{tabular}

Adding pyrazinamide as a third drug made little difference to the results, but giving an initial intensive phase made an important difference, for $88 \%$ of the patients had quiescent disease at a year. The reasons for the inferiority of the three once-weekly regimens is both interesting and important. Table 8 sets out the proportions attaining bacteriologically quiescent disease for the slow and for the rapid inactivators of isoniazid, separately. On the twice-weekly regimen the results were very similar: $97 \%$ of the slow and $91 \%$ of the rapid inactivators attained quiescent disease at a year, proportions which, in a larger series of patients, became practically identical at $92 \%$ and $91 \%$ respectively (Tuberculosis Chemotherapy Centre, Madras, 1970). In contrast, there was a substantial difference between the level of success in

TABle 8. Quiescent disease at 1 year in slow and rapid inactivators of isoniazid (Madras Study of once-weekly chemotherapy, 1970)

\begin{tabular}{lcc}
\hline & \multicolumn{2}{c}{$\begin{array}{c}\text { Patients with quiescent } \\
\text { disease }\end{array}$} \\
\cline { 2 - 3 } Regimen & Isoniazid inactivation rate \\
\cline { 2 - 3 } & Slow (\%) & Rapid (\%) \\
\hline SHTW & 97 & 91 \\
SH/SHOW & 95 & 76 \\
SHZOW & 87 & 53 \\
SHOW & 76 & 56 \\
\hline
\end{tabular}


the slow and rapid inactivators of isoniazid for all the three once-weekly regimens, the rapid inactivators being at a substantial disadvantage. It will also be seen that the slow inactivators on the SH/SHOW regimen achieved the same level of quiescence as the patients on the SHTW regimen. It is clear that if a method to compensate for the isoniazid deficiency which exists in rapid inactivators of the drug can be found, then once-weekly chemotherapy will be a practicability. Possible methods of achieving this have been referred to elsewhere (Fox, 1968), but the prospects are indeed good. However, already the Tuberculosis Chemotherapy Centre, Madras (Menon, 1970; Nazareth, 1970; Tripathy, 1970) has studied possible ways of strengthening the $\mathrm{SH} / \mathrm{SHOW}$ regimen (defined above). Both the influence of a higher (17 mg/kg body-weight) dose in comparison with a lower $(13 \mathrm{mg} / \mathrm{kg})$ dose of isoniazid in compensating for the isoniazid deficiency in rapid inactivators and also the role of PAS has been studied. PAS, in addition to acting as a third drug, also competes with isoniazid for acetylation by the liver, thus indirectly increasing the serum isoniazid level. It will be seen (Table 9) that neither the addition of PAS nor an increase in the dosage of isoniazid is effective, and unfortunately a further increase in the dosage of isoniazid is not possible because of the risk of acute toxicity.

The role of a 3-month initial intensive phase is currently under investigation in a Czechoslovakian Tuberculosis Service/WHO/British Medical Research Council co-operative study. An alternative approach of developing a slow release preparation of isoniazid also holds out promise, the aim being to develop a preparation which is therapeutically effective in rapid inactivators whilst avoiding toxicity in slow inactivators.

\section{Current attitudes to intermittent chemotherapy}

It remains to consider current attitudes to intermittency and these may be considered at a national level and at an individual physician level.

TABLE 9. Quiescent disease at 1 year in slow and rapid inactivators of isoniazid in Madras Study of two once-weekly regimens (Nazareth, 1970)

\begin{tabular}{|c|c|c|c|c|}
\hline \multirow{3}{*}{$\begin{array}{l}\text { Isoniazid } \\
\text { inactivation } \\
\text { rate }\end{array}$} & \multicolumn{4}{|c|}{ Regimen } \\
\hline & \multicolumn{2}{|c|}{$\begin{array}{c}\text { SH daily } \\
\text { SH once-weekly }\end{array}$} & \multicolumn{2}{|c|}{$\begin{array}{c}\text { SPH daily } \\
\text { SPH once-weekly }\end{array}$} \\
\hline & No. & $\%$ & No. & $\%$ \\
\hline $\begin{array}{l}\text { Slow } \\
\text { Rapid } \\
\text { Both groups }\end{array}$ & 176 & $\begin{array}{l}93 \\
72 \\
85\end{array}$ & 170 & $\begin{array}{l}95 \\
76 \\
87\end{array}$ \\
\hline
\end{tabular}

(a) At a national level

(1) There are some countries in which the declared policy is to use only supervised intermittent regimens of chemotherapy. This does seem to be an extreme approach, especially for developing countries.

(2) In some countries, no notice for all practical of purposes has been taken of intermittency, which has either been ignored or else regarded as of no relevance. This represents a complete failure to appreciate the importance of intermittency, or why it should be introduced.

(3) There is an intermediate situation in which intermittency is recommended as an alternative approach to chemotherapy, standard daily regimens and intermittent regimens being regarded as constituting alternative but complementary approaches to chemotherapy. This is the current official governmental approach in India.

\section{(b) At an individual physician level}

(1) Some physicians only use intermittent regimens for all their patients, even those with trivial lesions who are consistently bacteriologically negative on diagnostic culture examination. Further, they pre cede intermittency by an initial intensive phase of daily chemotherapy even for as long as 3 months $\mathbb{D}$ This is a quite extreme and unnecessarily aggressive approach to chemotherapy.

(2) There are other physicians who never use inter mittency at all and claim they have no difficulties whatsoever with standard chemotherapy wit streptomycin PAS and isoniazid. This is the other extreme point of view, demonstrating an inflexibility of approach to and lack of appreciation of the problems of patient supervision and co-operation in treatment.

(3) There is an intermediate approach in which physicians use both methods of chemotherapy and organize supervised intermittency for certain of their patients. As an example are the patients that they feel are undependable in the regular self-administration of their medicament. Equally, it may be so simple to organize fully supervised intermittent chemotherapy for some patients, such as those working in a factory with a dispensary on the spot, that there is no reason whatever why the patient should not be given supervised chemotherapy and why any risk of failure to co-operate in self-administered chemotherapy should be run.

Both at a national level and at an individual physician level the intermediate dual approach using both unsupervised daily and supervised intermittent regimens does now seem to be the most appropriate one to adopt. However, as the number of patients needing treatment declines, then more and more will it be likely both that national policies and the policy 
of individual physicians should and will move more and more in favour of fully supervised chemotherapy, at least for confirmed cases of active disease.

\section{References}

Canetti, G., Grumbach, F. \& Grosset, J. (1963) Long-term, two-stage chemotherapy of advanced experimental murine tuberculosis with intermittent regimens during the second stage. Tubercle, 44, 236.

Chambers, J., Katz, S., McCormick, G., Gimble, A., Leonard, J., Schmidt, W. \& Shea, J. (1955) Follow-up report on the use of intermittent streptomycin and isoniazid in pulmonary tuberculosis. Transactions of the Fourteenth Conference on the Chemotherapy of Tuberculosis, Veterans Administration, p. 107.

CORPER, H.J. \& COHN, M.L. (1964) The remote sustained threshold therapeutic action of streptomycin in tuberculosis. Science, 106, 446.

Czechoslovakian Tuberculosis Service/World Health Organisation/British Medical Research Council CoOPERATIVE INVESTIGATION (1971) A comparison of standard and fully intermittent continuation regimens including a comparison of two durations of sanatorium stay. Bulletin of the World Health Organisation (in press).

Decroix, G., Kreis, B., Sors, C., Birenbaum, Le Lirzin, M. \& Canetri, G. (1971) Etude comparative du traitement de la tuberculose pulmonaire par l'association rifampicineisoniazide administrée quotidiennement et deux. fois par semaine pendant une année. Revue de Tuberculose et de Pneumologie, 35, 39.

Devadatta, S., Menon, N.K., Nazareth, O., RadhakrishNA, S., RAMAKRISHNaN, C.V., SOMASUndaram, P.R., Usha, S.P. \& Velu, S. (1970) A double-blind study to determine the maximum tolerated dose of ethionamide, when administered twice-weekly to patients with pulmonary tuberculosis. Tubercle, 51, 263.

Dickinson, J.M. \& Mitchison, D.A. (1966a) In vitro studies on the choice of drugs for intermittent chemotherapy of tuberculosis. Tubercle, 47, 370.

Dickinson, J.M. \& Mirchison, D.A. (1966b) Short-term intermittent chemotherapy of experimental tuberculosis in the guinea-pig. Tubercle, 47, 381 .

Dickinson, M.J., Ellard, G.A. \& Mitchison, D.A. (1968) Suitability of isoniazid and ethambutol for intermittent administration in the treatment of tuberculosis. Tubercle, 49, 351.

Fox, W. (1968) The John Barnwell Lecture: Changing concepts in the chemotherapy of pulmonary tuberculosis. American Review of Respiratory Disease, 97, 767.

Fox, W., Robinson, D.K., Tall, Ruth, Mitchison, D.A., Kent, P.W. \& Macfadyen, D.M. (1969) A study of acute intolerance to ethionamide, including a comparison with prothionamide, and of the influence of vitamin B-complex additive in prophylaxis. Tubercle, 50, 125.

Frimodt-Møller, J., Jesudian, K.T., Muthiah, T.S. \& BARTON, R.M. (1953) The effect of isoniazid in pulmonary tuberculosis as judged by control studies in Indian patients. Indian Journal of Tuberculosis, 1, 23.

Gangadharam, P.R.J., Devadatta, S., Fox, W., Narayanan NaIR, C. \& Selkon, J.B. (1961) Rate of inactivation of isoniazid in South India patients with pulmonary tuberculosis: 3. Serum concentrations of isoniazid produced by three regimens of isoniazid alone and one of isoniazid plus PAS. Bulletin of the World Health Organisation, 25, 793.

GrumbaCH, F., Rist, N. \& RiEbEL, J. (1952) Traitement discontinu de la tuberculose experimentale de la souris par l'hydrazide isonicotinique. Annals of the Institut Pasteur (Paris), 83, 397.
Grumbach, F. (1962) Treatment of experimental murine tuberculosis with different combinations of isoniazid/ streptomycin followed by isoniazid alone. American Review of Respiratory Disease, 86, 211.

Grumbach, F., Canetti, G. \& Grosset, J. (1964) Further experiments on long-term chemotherapy of advanced murine tuberculosis, with emphasis on intermittent regimens. Tubercle, 45, 125.

Grumbach, F., Canetti, G., Grosset, J. \& Le Lirzin, M. (1967) Late results of long-term intermittent chemotherapy of advanced, murine tuberculosis: Limits of the murine model. Tubercle, 48, 11.

Grumbach, F., Canetti, G. \& Le Lirzin, M. (1969) Rifampicin in daily and intermittent treatment of experimental murine tuberculosis, with emphasis on late results. Tubercle, 50, 280.

Hobby, G.L. \& LenerT, T.F. (1953) The control of experimental mouse tuberculosis by the intermittent administration of streptomycin, viomycin, isoniazid and streptomycyclidene isonicotinyl hydrazine. American Review of Respiratory Disease, 68, 292.

Hutton, P.W., Lutalo, Y.K., Williams, A.W., Tonkin, I.M. \& Fox, W. (1956) Acute pulmonary tuberculosis in East Africans: A controlled trial of isoniazid in combination with streptomycin or PAS. Tubercle, 37, 151.

INTERNATIONAL UNION Against TUbERCUlosis INVESTIGaTION (1970) A controlled trial of three regimens of selfadministered and supervised chemotherapy for pulmonary tuberculosis. Bulletin of the International Union Against Tuberculosis, 44, 8 .

LAHLOU, M. (1970) Comparaison de deux regimes therapeutiques intermittents: ethionamide-isoniazide et streptomycine-isoniazide. Proceedings of the XXth International Tuberculosis Conference, New York, 2-6 September 1969. Bulletin of the International Union Against Tuberculosis, 43, 289.

MACKAY-Dick, J. (1954) Nursing the tuberculous. Lancet, ii, 44.

MACKAY-Dick, J. (1959) Chemotherapy in tuberculosis. British Medical Journal, $2,100$.

MENON, N.K. (1970) Madras study of two once-weekly regimens: Clinical aspects. Proceedings of the XXth International Tuberculosis Conference, New York, 2-6 September 1969. Bulletin of the International Union Against Tuberculosis, 43, 271.

Medical Research Council (1955) Various combinations of isoniazid with streptomycin or with PAS in the treatment of pulmonary tuberculosis. Seventh report to the Medical Research Council by their Tuberculosis Chemotherapy Trials Committee. British Medical Journal, 1, 435.

Mitchison, D.A. (1970) Bacteriological mechanisms in recent controlled chemotherapy studies. Proceedings of the XXth International Tuberculosis Conference, New York, 2-6 September 1969. Bulletin of the International Union Against Tuberculosis, 43, 322.

Mount, F.W. \& Ferebee, S.H. (1953) Control study of comparative efficacy of isoniazid, streptomycin-isoniazid, and streptomycin-para-aminosalicylic acid in pulmonary tuberculosis therapy: III. Report on 28-week observations on 649 patients with streptomycin-susceptible infections. American Review of Respiratory Disease, 67, 539.

NAZARETH, M.O.Y. (1970) Madras study of two supervised once weekly regimens. Proceedings of the Twenty-fifth National Conference on Tuberculosis and Chest Diseases, p. 184.

Palmer, C.E., Ferebee, S.H. \& Hopwood, L. (1956) Studies on prevention of experimental tuberculosis with isoniazid: II. Effects of different dosage regimens. American Review of Respiratory Disease, 74, 917.

Polansky, F. (1970) Trial of sanatorium treatment including 
a comparison of standard and intermittent continuation chemotherapy: Central Bohemian Tuberculosis Services/ WHO/British Medical Research Council. Proceedings of the XXth International Tuberculosis Conference, New York, 2-6 September 1969. Bulletin of the International Union Against Tuberculosis, 43, 295.

RAMAKRISHNAN, C.V. (1971) Supervised twice-weekly chemotherapy with PAS and isoniazid in South Indian patients suffering from pulmonary tuberculosis. Proceedings of the 26th National Conference on Tuberculosis and Chest Diseases, Bangalore, 3 January 1971 (in press).

SchWARTZ, W.S. (1956) A comparison of daily streptomycin and daily isoniazid versus biweekly streptomycin and daily isoniazid: Pilot study III-B. Transactions of the Fifteenth Conference on the Chemotherapy of Tuberculosis, Veterans Administration, p. 54.

Stradling, P. (1971) Potentially serious side-effects of high dose twice-weekly rifampicin. British Medical Journal (in press).

Tempel, C.W., Hughes, F.J., Mardis, R.E., Towbin, M.N. \& DYE, W.E. (1950) Combined intermittent regimens employing streptomycin and paraminosalicylic acid in the treatment of pulmonary tuberculosis. Transactions of the
Ninth Streptomycin Conference, Veterans Administration, p. 36.

TripathY, S.P. (1970) Madras study of two once-weekly regimens. Laboratory aspects. Proceedings of the XXth International Tuberculosis Conference, New York, 2-6 September 1969. Bulletin of the International Union Against Tuberculosis, 43, 276.

Tripathy, S.P. (1971) Personal communication.

Tuberculosis Chemotherapy Centre, Madras (1960) A concurrent comparison of isoniazid plus PAS with three regimens of isoniazid alone in the domiciliary treatment of pulmonary tuberculosis in South India. Bulletin of the World Health Organisation, 23, 535.

Tuberculosis Chemotherapy Centre, Madras (1964) A concurrent comparison of intermittent (twice-weekly) isoniazid plus streptomycin and daily isoniazid plus PAS in the domiciliary treatment of pulmonary tuberculosis. Bulletin of the World Health Organisation, 31, 247.

Tuberculosis Chemotherapy Centre, Madras (1970) A controlled comparison of a twice-weekly and three onceweekly regimens in the initial treatment of pulmonary tuberculosis. Bulletin of the World Health Organisation, 43, 143. 